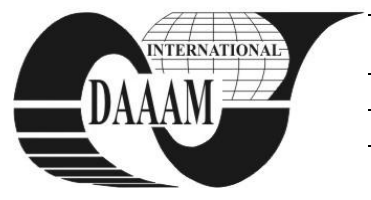

\title{
EVALUATION OF OPERATIONAL TIMES BY MTM METHODS IN THE DIGITAL FACTORY ENVIROMENT
}

\author{
KURKIN, O[ndrej] \& BURES, M[arek]
}

\begin{abstract}
In this time of globalization, when every company needs to stay competitive to survive in the market, it is still more necessary to reduce costs, streamline production, innovate the product or whole production systems etc. This contribution is focused on using the concept of digital factory in the planning phase, specifically on setting operation times in a packing workplace. Times are set by two methods, MTM1 and UAS. After this planning phase, the process is simulated in a virtual environment. After simulations and experiments with virtual workplace, we created a real workplace, and conducted real experiments. At the end of the paper is a comparison between real and virtual workplaces.
\end{abstract}

Key words: MTM, UAS, simulation, verification, digital factory

\section{INTRODUCTION}

Digital factory is a picture of real production which represents manufacturing processes in a virtual environment. It is mainly used for planning operations, simulation and optimization of dificult products such as automobiles, airplanes, ships etc. Especially in these industries, the terms Digital factory, digital manufacturing appear still more and more. This is because you can test, or experiment or verify many decisions in a virtual environment, and you do not risk any problems in real production or a real system. (Harris et al., 2003)

\section{CASE STUDY}

As an example of planning in a virtual environment, we chose a workplacewhere an operator is packaging screws and a small wrench into a small sack. This full sack continues to the assembly line. Every finished product contains this sack, with screws and tools. In figure 1 is shown a planned space arrangement of a future workplace. Each box is marked by a number from $\boldsymbol{I}$ to $\boldsymbol{6}$. The box with letter $\boldsymbol{S}$ is for a sack, and the box for full sacks is marked with out. Length is in milimeters.

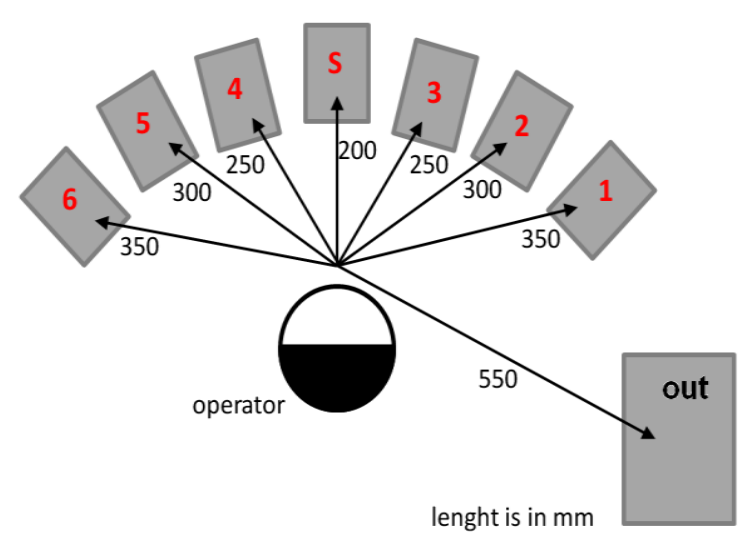

Fig. 1. Workplace schema

\subsection{Experiment procedure}

The whole study is divided into eight steps:

1. Creating workplace schema (fig. 1).

2. Preliminary setting of the operation times by MTM 1

3. Setting operation times with Process Designer using the UAS method.

4. Design of a virtual workplace using the Tecnomatix Process Designer by SIEMENS Plm Software.

5. Verification of the times using continous dynamic simulation

6. Creating a real workplace

7. Real experiment and time measurement

8. Evaluation of the experiment

\subsection{Setting times with MTM1}

MTM1 method serves to set operation times. This method is based on dividing the operation into particular movements. Every movement has a code and the time which is consumed by this movement. After completing these times/codes we have a final time for the operation. There are many methods for setting these operation times such as MTM1, MTM2, UAS, MEK, MOS, SBW etc.

We used MTM1 for setting preliminary times, and UAS method for setting times in digital factory in this case study.

We have a final time of 15.0192 seconds using MTM1 method (time is for one cycle of operation - operator takes sack, and puts first screw into the sack, then second part, third etc.. and the last movement is taking a new sack)

\subsection{Setting times with Process Designer}

Now we must set the times the same way as in chapter 2.2, but not with MTM1. We will use UAS method, which is part of a process Designer. After defining times, the final time is 16.20 seconds.

You can see then each method has different final results. This is because MTM1 is more detailed than UAS. For example, if we want to define the movement of a hand using MTM1, you must set opening fingers, closing fingers etc. If you want make the same operation with UAS, you must set get and place operation and that is all, closing and opening fingers are included in this get and place operation.

\subsection{Creating a workplace with Process Designer}

We created a virtual model of the workplace in the virtual environment of the process designer. Now, we can make experiments and simulations. This workplace is completed with components which we created. These components are exactly the same as real componets from catalogues etc. We also set a price for each component.(Votava et al., 2008)

Depending on the results of simulations and experiments, we can make changes (for example changes to the space arrangement, we can put a work table lower/higher, we can put a chair lower/higher etc. We can also see how the costs changefor example, if we want to buy another box, or if we want a different box. This is a very useful advantage. 


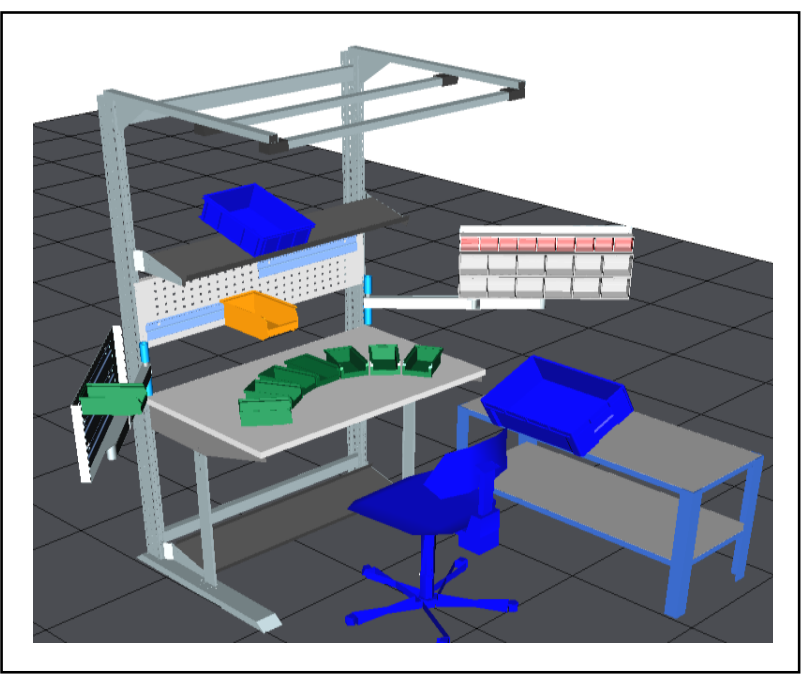

Fig. 2. Computer model of the workplace

\subsection{Simulation of the operation with Process Simulate}

After defining the whole process (defining resources, products and operations) it is time for simulations and making any corrections. These simulations can provide better times which are closer to the real times.(Srajer, 2010)

This is because MTM methods (also UAS and others) define movements in distances $0-200 \mathrm{~mm}, 200-500 \mathrm{~mm}$ and 500 $800 \mathrm{~mm}$. If there is a movement of $650 \mathrm{~mm}$, MTM methods (in virtual model) set the same time for $500 \mathrm{~mm}, 600 \mathrm{~mm}$ to $800 \mathrm{~mm}$. The real time will be different. Dynamic simulation provides times which are exactly consumed by the movements.

Based on the design of the workplace in the virtual environment, we have created a real workplace in our laboratory. This workplace is exactly the same as the computer model (dimensions of worktable, height of chair, and also hight of the operator) (Ciriello, 1991).

In figure 3 is shown the real workplace where we conducted the experiments, and a virtual worplace where we made simulations.

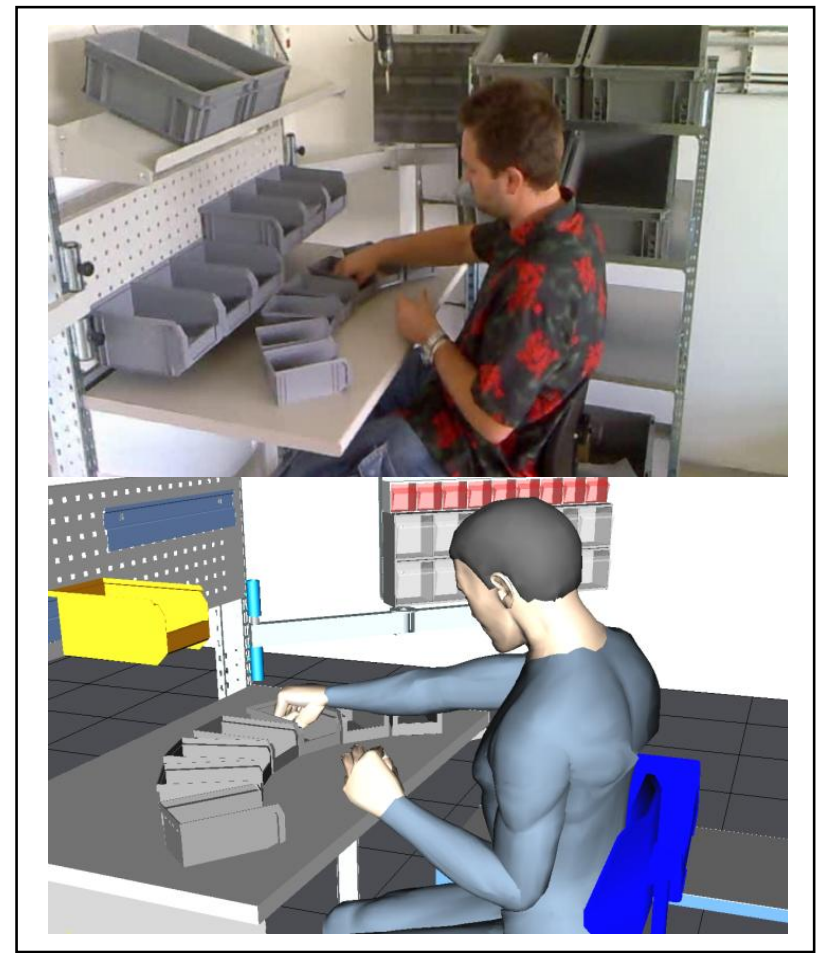

Fig. 3. Real and virtual workplace

\section{CONCLUSION}

The aim of this paper is to show the benefits of using the digital factory concept in the planning phase. You can use this concept for setting the operation times which are consumed in operations, or for example for optimization of space arrangement and ergonomics of workplaces.

The biggest advantage of the model in the virtual environment is the possibility to make corrections and modifications of a whole process and we do not have to stop a real process. Another big advantage is the testing of the manufacturing and variants of the procesess in the planning phase of production. In table 1 is a comparison of the result times. You can see that every method has a different time, but the simulation is very close to real times.

\begin{tabular}{|c|c|c|c|}
\hline \multicolumn{4}{|c|}{ Opration times (sec) } \\
\hline MTM1 & UAS & Simulation & Real. exp. \\
\hline 15.0192 & 16.20 & 16.83 & ${ }^{*} 17.60$ \\
\hline
\end{tabular}

Tab. 1. Comparison of the times

*average from 10 measurements

After evaluating the variants, we can apply the best variant to the real system. We can be sure that there will be no problems such as wrong supplies to the workplaces, nonergonomic environment etc. (Philips, 1997). The vision for the future is that there will be no prototyping because of the concept of a digital factory.

\section{ACKNOWLEDGEMENTS}

This paper was supported by the Grant Agency in the Czech Republic (GA CR). Project No. 402/08/H051: Optimizing of multidisciplinary designing and modeling of production system of virtual enterprises.

\section{REFERENCES}

Ciriello, V. M.; Snook, S. H. (1991). The design of manual handling tasks: revised tables of maximum acceptable weights and forces. Ergonomics, 34, 1197-1213

Harris, R.; Harris, Ch. \& Wilson, E. (2003). Making materials flow: a lean material-handling guide for operations, production-control, and engineering professionals, Lean Enterprise Institute, ISBN 0974182494, Cambridge

Philips, J. E. (1997). Manufacturing plant layou: Fundamentals and Fine Points of Optimum Facility Design, Society of Manufacturing Engineers, ISBN 0-87263-484-1, Dearborn Michigan

Srajer, V.; Miller, A. \& Simon, M. (2010). Importance of the proposal layout for increasing competitiveness enterprise, Annals of DAAAM for 2010 \&Proceedings of The 21th international DAAAM symposium,20-23rd October 2010, Zadar, Croatia, ISSN 1726-9679, ISBN 978-3-901509-735, Katalinic, B. (Ed.), pp. 0787-0788, Published by DAAAM International Vienna, Vienna

Votava, V.; Ulrych, Z.; Edl, M.; Korecký, M. \& Trkovský, V. (2008). Analysis and Optimization of Complex Small - Lot Production in New Manufacturing Facilities Based on Discrete Simulation, 20th European Modeling \& Simulation Symposium (EMSS 2008), Bruzzone, A. (Ed.), pp. 198-203, ISBN 978-88-903724-0-7, Campora San Giovanni, Amantea, Italy, September 2008, Diptem Universita di Genova, Genova 